\title{
Quercetin with the potential effect on allergic diseases
}

\author{
Morteza Jafarinia ${ }^{1}$, Mahnaz Sadat Hosseini ${ }^{1}$, Neda kasiri ${ }^{1}$, Niloofar Fazel ${ }^{1}$, Farshid Fathi ${ }^{1}$, \\ Mazdak Ganjalikhani Hakemi ${ }^{1}$ and Nahid Eskandari ${ }^{1,2^{*}}$
}

\begin{abstract}
Quercetin is a naturally occurring polyphenol flavonoid which is rich in antioxidants. It has anti-allergic functions that are known for inhibiting histamine production and pro-inflammatory mediators. Quercetin can regulate the Th1/ Th2 stability, and decrease the antigen-specific IgE antibody releasing by B cells. Quercetin has a main role in antiinflammatory and immunomodulatory function which makes it proper for the management of different diseases. Allergic diseases are a big concern and have high health care costs. In addition, the use of current therapies such as B2-agonists and corticosteroids has been limited for long term use due to their numerous side effects. Since the effect of quercetin on allergic diseases has been widely studied, in the current article, we review the effect of quercetin on allergic diseases, such as allergic asthma, allergic rhinitis (AR), and atopic dermatitis (AD).
\end{abstract}

Keywords: Quercetin, Allergy, Asthma

\section{Background}

Medicinal plants are become more popular in the last decades regard to their low price, natural origin, and fewer side effects [1]. Studies indicated several plantderived secondary metabolites that can down-regulate the expression and production of inflammatory mediators and their receptors and inhibit the expression of transcription factors which are promoting the secretion of mediators [2]. Researchers are attributing quercetin as one of the well-known types of plant's metabolites [2]. Quercetin (3,31,41,5,7-pentahydroxyflavone), a naturally occurring polyphenol flavonoid, found in some fruits and vegetables, including onions, capers, apples, berries, tea, tomatoes, grapes, Brassica vegetables, and shallots, as well as many nuts, seeds, barks, flowers, and leaves $[3,4]$. The highest concentration of quercetin is $234 \mathrm{mg} / 100 \mathrm{~g}$ of edible portion in capers (raw) and the

*Correspondence: neskandari@med.mui.ac.ir

${ }^{1}$ Department of Immunology, Faculty of Medicine, Isfahan University of Medical Sciences, Box 8174673461, Isfahan, Iran

Full list of author information is available at the end of the article lowest concentration is $2 \mathrm{mg} / 100 \mathrm{~g}$ of edible portion in black or green tea (Camellia sinensis) [5].

Therefore, quercetin is one of the main flavonoids in our diet and our body requires between 5 and $40 \mathrm{mg}$ daily uptakes of it. Quercetin is largely metabolized in the intestine and liver. The plasma level of quercetin is normally in low ranges, but after consuming foods that are highly rich in it, the plasma's level of it increase to different ranges. Quercetin contains 3 rings and 5 -hydroxyl group (Fig. 1) and it is naturally found in plants as a glycone or carbohydrate conjugates [6-8].

There are several potential benefits of total health and disease resistance such as anti inflammatory, antioxidant and also the ability to inhibit lipid peroxidation, platelet aggregation and capillary permeability [9]. Antiinflammatory effect of quercetin has been shown in several studies. Quercetin inhibits lipopolysaccharide (LPS)-induced tumor necrosis factor alpha (TNF$\alpha)$ production in macrophages [10], LPS-induced interleukin (IL)-8 production in lung A54 cells [11], LPSinduced mRNA levels of TNF- $\alpha$ and IL- $1 \alpha$ in glial cells [12], production of inflammation-producing enzymes (cyclooxygenase (COX) and lipoxygenase (LOX) [13], and 
<smiles>O=c1c(O)c(-c2ccc(O)c(O)c2)oc2cc(O)cc(O)c12</smiles>

Fig. 1 Structure of quercetin

FceRI-mediated release of proinflammatory cytokines, tryptase, and histamine from human umbilical cord blood-derived cultured mast cells [14]. Based on different effects of quercetin, we review the effect of quercetin on allergic asthma, allergic rhinitis (AR), and atopic dermatitis (AD) in this article.

\section{Allergic asthma}

Asthma is a chronic inflammatory lung disease. The typical signs of asthma include airway obstruction, wheezing, and airway hyperresponsiveness. It characterized by airway hyperresponsiveness to allergens, airway edema, increased mucus secretion by the recruitment of eosinophils and other leukocytes, airway smooth muscle hypertrophy/hyperplasia, systemic immunoglobulin $\mathrm{E}$ (IgE) production and mucus hypersecretion [15-18]. The etiology of asthma is multifactorial and it seems that combinations of genetic and environmental factors are involved. Allergic asthma is mediated by $\mathrm{CD} 4^{+} \mathrm{T}$ cell immune reactions. $\mathrm{T}$ helper (Th) 1 and Th17 cells increase neutrophil recruitment and Th9 cells effectively change the mucus production, mast cell recruitment, and IgE production. $\mathrm{CD} 8^{+} \mathrm{T}$ cells, NKT cells, and $\gamma \delta \mathrm{T}$ cells are also able to modulate asthma associated inflammation and/or airway hyperresponsiveness. $\mathrm{T}$ regulatory (Treg) cells are known as innate suppressors and adaptive immune responses and also the factors for reducing inflammation. Th2 immune response is one of the most essential factors that are linked with the pathology of asthma. Cytokines produced by the Th2 cells in asthma (IL4, IL-5, IL-13) have a critical role in the inflammatory response. Cytokines, including IL-4, stimulate B cells to synthesize IgE, IL-13, and IL-5 which are required for eosinophilic access to the lung tissue in order to increase vascular permeability and chemotaxis, that can improve the inflammatory response. Besides, activated mast cells are able to release inflammatory and bronchoconstrictor mediators during an allergen challenge [19-21]. Most allergens or helminth-antigen-specific human $\mathrm{T} \mathrm{CD}_{4}^{+}$ cell clones exhibit a Th2 phenotype. In allergic diseases, Th1/Th2 balance shifts to Th2 phenotype [22]. History of atopic diseases is the strongest risk factor for developing asthma. People suffering from hay fever or eczema are more probable to allergic asthma. Environmental triggers for asthma include exercise, pollutants, hyperventilation, and hormonal change. Both indoor and outdoor allergens and pollutants including biological allergens (dust mites, cockroaches, mold, and animal dander), irritant chemicals, fumes-traffic pollution, high ozone level, and product by combustion device are important [23].

Asthma treatment is based on inhaled corticosteroids, $\beta 2$-agonists, anti-cholinergic, and methylxanthines. While using mentioned drugs alone or as a combination has a great effect, some side effects limit their usage. Thus, it is essential to develop new compounds having similar therapeutic potential and less adverse effects on the constant treatment of respiratory diseases [19]. In the following, the in vitro and in vivo effects of quercetin on allergic asthma are reviewed.

\section{Effect of quercetin on allergic asthma In vitro studies}

Most studies have investigated the impact of quercetin on tracheal tissue contractility and mucin 5 AC (MUC5AC). In 2009, the effect of quercetin on isolated tracheal tissue from male Wistar rats has been evaluated by Capasso et al. They showed quercetin (in concentrations of $10^{-6}-3 \times 10^{-4} \mathrm{M}$ ) inhibits rat tracheal contractility through a presynaptic and a postsynaptic site of action. They concluded that quercetin could be considered as a possible application in airways diseases such as asthma [24]. Two studies have been investigated the effect of quercetin on MUC5AC in allergic asthma. In 2010, Chang et al. indicated the dietary polyphenols ([6]-gingerol, epigallocatechin gallate (EGCG), curcumin, and quercetin) inhibit MUC5AC gene expression in NCI-H292 cells, and also their effect on ciliary beat frequency $(\mathrm{CBF})$ of the human nasal mucosa. The minimum inhibitory concentration of MUC5AC in quercetin was $40 \mu \mathrm{M}$. They concluded that Gingerol, quercetin, and EGCG may be considered as antihypersecretory agents because they effectively inhibit mucus secretion of respiratory epithelial cells while maintaining normal nasal ciliary movement [25]. In the same year, the effect of quercetin on MUC5AC expression induced by human neutrophil elastase (HNE) in human airway epithelial (HBE16) cells and its molecular mechanisms has been investigated by Li et al. They pretreated HBE16 cells with quercetin and also treated with HNE. Their results suggest that quercetin can inhibit HNE-induced MUC5AC expression in human airway epithelial cells through protein kinase $\mathrm{C}(\mathrm{PKC}) /$ epidermal growth factor receptor (EGFR)/extracellularregulated kinase (ERK) signal transduction pathway. The significant inhibitory dose for quercetin was $40 \mu \mathrm{M}$ 
[26] (Table 1). In vitro studies of quercetin suggest that quercetin in the concentration of $40 \mu \mathrm{M}$ is useful for mucus hypersecretion, a common pathological change in chronic inflammatory diseases of the airway. In the future, quercetin might be a valuable treatment for mucin hypersecretion in chronic inflammatory airway diseases in the clinic.

\section{In vivo studies}

Most of the in vivo studies have focused on the effects of quercetin on immunological aspects of asthma, such as cytokine levels, recruitment of leukocytes, and regulation of Th1/Th2 balance.

Two studies have been investigated the effect of quercetin in the immediate phase response (IAR) and late-phase response (LAR) of allergic reactions. In 2007, the effects of quercetin and rutin on asthmatic responses which were studied in ovalbumin (OVA)-sensitized conscious guinea-pigs challenged with aerosolized-OVA (aOVA) have been considered by Jung et al. Quercetin and rutin inhibited the specific airway resistance (sRaw) in LAR and IAR dose-dependently, as well as the recruitment of leukocytes, particularly eosinophils and neutrophils on LAR. Also, quercetin and rutin $(7.5 \mathrm{mg} /$ $\mathrm{kg}$ ) inhibited sRaw and leukocyte recruitment at a similar level as dexamethasone in LAR and salbutamol in IAR. Thus, they indicated quercetin and rutin may be useful in the treatment of IAR and LAR in asthma [21]. The effects of quercetin inhalation on IAR, LAR and late LAR (LLAR) asthmatic responses with exposure to aOVA which were studied in conscious guinea-pigs sensitized with aOVA have been investigated by Moon et al. Quercetin $(10 \mathrm{mg} / \mathrm{ml})$ significantly decreased histamine and protein contents, phospholipase (PL) A2 activity, and recruitments of leukocytes in bronchoalveolar lavage fluid (BALF) and also slightly increased infiltration of eosinophils and neutrophils in the histopathological survey. Quercetin's anti-asthmatic activity was similar to cromolyn sodium and dexamethasone [27].

In allergic diseases, Th1/Th2 balance shifts to Th2 phenotype, so investigation on the effect of quercetin on Th1/Th2 balance seems to be essential. In 2009, quercetin's role in regulation of Th1/Th2 balance and cytokine production, $\mathrm{T}$-box protein expressed in $\mathrm{T}$ cells (T-bet) and GATA-3 gene expression in OVA-induced asthma model mice (BALB/c mice) has been studied by Park et al. Mice were injected intraperitoneal with 8 or $16 \mathrm{mg} / \mathrm{kg} /$ day in $200 \mu \mathrm{l}$ of quercetin each day. Results strongly indicated that quercetin decreased allergic airway inflammation and hyperresponsiveness due to the alteration of Th1/Th2 differentiation via the suppression of GATA-3 and the increase of T-bet expression. They also showed that quercetin reduced the increased levels of IL-4, increased interferon (IFN)- $y$, and significantly inhibit all asthmatic reactions. They suggested that quercetin might be a new therapeutic line to the allergic airway diseases (Fig. 2) [20]. In 2008, Zhu et al. studied Elaeagnus pungens leaf that confirming to be very operative for the treatment of asthma and chronic bronchitis as traditional Chinese medicine. Quercetin seems to be the major effective components of Elaeagnus pungens leaf. They suggested that quercetin and kaempferol are effective in treating asthma and chronic bronchitis [28]. There were also some other studies that investigated on the leukocyte counts and cytokine levels in BALF. The study of Rogerio et al. in 2007 have shown that in BALB/c receiving quercetin $(10 \mathrm{mg} / \mathrm{kg})$, eosinophil counts were lower in BALF, blood and lung parenchyma [29]. The same group in 2010 compared the anti-inflammatory effects of quercetin-loaded microemulsion (QU-ME) and quercetin suspension (QU-SP) in an experimental model of airways allergic

Table 1 Summary of main effects of quercetin on allergic diseases (in vitro studies)

\begin{tabular}{|c|c|c|c|c|c|}
\hline Diseases & Dosage & Cell/cell line & Animal & Quercetin's effect & References \\
\hline \multirow[t]{3}{*}{ Allergic asthma } & $10^{-6}-3 \times 10^{-4} \mathrm{M}$ & Tracheal tissue & Male Wistar rat & Inhibits rat tracheal contractility & {$[24]$} \\
\hline & $40 \mu \mathrm{M}$ & $\mathrm{NCl}-\mathrm{H} 292$ cells & $\mathrm{n} / \mathrm{a}$ & Inhibit MUC5AC gene expression & {$[25]$} \\
\hline & $40 \mu \mathrm{M}$ & HBE16 & $\mathrm{n} / \mathrm{a}$ & $\begin{array}{l}\text { Inhibit HNE-induced MUC5AC expression in human airway } \\
\text { epithelial cells through PKC/EGFR/ERK signal transduction } \\
\text { pathway }\end{array}$ & {$[26]$} \\
\hline \multirow[t]{2}{*}{ Allergic rhinitis } & $4.0 \mu \mathrm{M}$ & HNEpC & $\mathrm{n} / \mathrm{a}$ & Suppressed the ability of cells to produce RANTES and eotaxin & {$[38]$} \\
\hline & $1.0 \mathrm{nM}$ & HNEpC & & $\begin{array}{l}\text { Modified the clinical condition of AR through the suppression of } \\
\text { NO production from nasal epithelial cells after IL-4 stimulation }\end{array}$ & {$[41]$} \\
\hline \multirow[t]{2}{*}{ Atopic dermatitis } & $30 \mu \mathrm{M}$ & $\mathrm{RBL}-2 \mathrm{H} 3$ & $\begin{array}{l}\text { Wistar rat and } \\
\text { BALB/C }\end{array}$ & $\begin{array}{l}\text { Upregulation of } \mathrm{HO} \text { after short exposure } \\
\text { Induction of } \mathrm{HO}-1 \text { expression after long exposure }\end{array}$ & {$[51]$} \\
\hline & $5 \mathrm{mg} / \mathrm{ml}$ & Keratinocyte & $\mathrm{n} / \mathrm{a}$ & $\begin{array}{l}\text { Strong ability to scavenge free radicals and protect human } \\
\text { keratinocytes against hydrogen peroxide damage }\end{array}$ & {$[52]$} \\
\hline
\end{tabular}

MUC5AC mucin 5 AC, HNE human neutrophil elastase, PKC protein kinase C, EGFR epidermal growth factor receptor, ERK extracellular-regulated kinase, RANTES regulated on activation, normal $T$ cell expressed and secreted, NO nitric oxide, $R A$ allergic rhinitis, $H O$ heme oxygenase, $H N E p C$ human nasal epithelial cells 


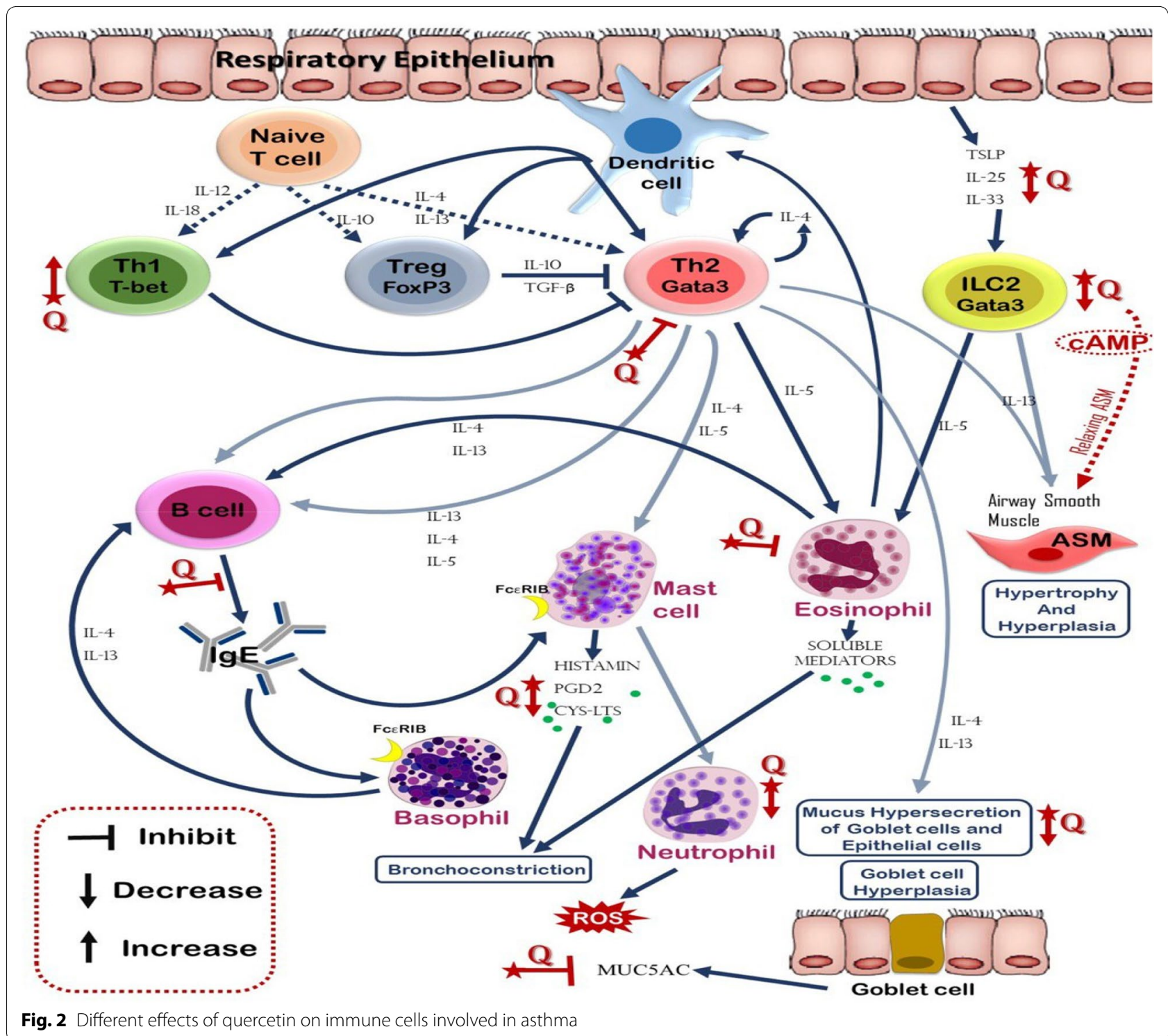

inflammation. Mice received a daily oral dose of QU-ME (3 or $10 \mathrm{mg} / \mathrm{kg}$ ) or QU-SP $(10 \mathrm{mg} / \mathrm{kg}$ ). Their results showed QU-ME reduced the eosinophil recruitment, IL-4 and IL-5 levels in the BALF, as well as, inhibited the nuclear transcription factor-kappa B (NF- $\mathrm{kB}$ ) activation, $\mathrm{P}$-selectin expression and the mucus production in the lung. As the plant-derived flavonoid quercetin is part of many foods and seems to be safe despite long-term use in animals and humans, therefore, its microemulsion would form an interesting and practical formulation to increase its oral bioavailability and, in turn, to evaluate its potential clinical advantage for treating certain inflammatory and allergic diseases [17]. In 2016, the influence of quercetin $(16 \mathrm{mg} / \mathrm{kg} /$ day $)$ on histopathological aspects and also airway epithelium in allergic airway inflammation on
BALB/c mice has been evaluated by Sozmen et al. Quercetin treatment cause lower epithelial thickness, subepithelial smooth muscle thickness, goblet, and mast cell numbers compared to untreated mice with allergic airway inflammation. However, quercetin treatment was not effective in improving basal membrane thickness. Immunohistochemical scores of IL-25, IL-33, Thymic stromal lymphopoietin (TSLP), cysteine-dependent aspartate-specific proteases (caspase)-3 and terminal deoxynucleotidyl transferase-mediated dUTP nick end labeling (TUNEL) were lower in quercetin-treated mice in comparison with untreated mice with allergic airway inflammation. IL-4, IL-25, IL-33, TSLP levels in BALF and OVA-specific IgE in serum were lower in quercetin treated mice compared with untreated mice. 
These results suggest that quercetin improves chronic histopathological changes except for basal membrane thickness in lung tissue and its beneficial effects on inflammation might be related to epithelium-derived cytokines modulators and epithelial apoptosis [31] (Table 2). Similar to in vitro studies, in vivo studies suggest that quercetin plays a critical role in asthmatic reactions. Anti-inflammatory effects of quercetin such as reduction of IL-4 and IgE in serum could be useful on allergic asthma.

\section{In vivo and in vitro studies}

Most in vivo and in vitro studies also have investigated the effect of quercetin on leukocyte and smooth muscle

Table 2 Summary of main effects of quercetin on allergic diseases (in vivo studies)

\begin{tabular}{|c|c|c|c|c|}
\hline Diseases & Dosage & Animal & Quercetin's effect & References \\
\hline \multirow[t]{7}{*}{ Allergic asthma } & $7.5 \mathrm{mg} / \mathrm{kg}$ & Male Dunkin-Hartley guinea pigs & $\begin{array}{l}\text { Inhibited the sRaw in LAR and IAR dose-dependently, } \\
\text { as well as the recruitment of leukocytes, particularly } \\
\text { eosinophils and neutrophils on LAR }\end{array}$ & {$[21]$} \\
\hline & $10 \mathrm{mg} / \mathrm{ml}$ & Male Dunkin-Hartley guinea pigs & $\begin{array}{l}\text { Decreased histamine and protein contents, PLA2 activity, } \\
\text { and recruitments of leukocytes in BAL fluid and } \\
\text { also slightly increased infiltration of eosinophils and } \\
\text { neutrophils in histopathological survey }\end{array}$ & {$[27]$} \\
\hline & 8 or $16 \mathrm{mg} / \mathrm{kg}$ & $\mathrm{BALB} / \mathrm{C}$ & $\begin{array}{l}\text { Decreased allergic airway inflammation and } \\
\text { hyperresponsiveness due to the alteration of Th1/ } \\
\text { Th2 differentiation via the suppression of GATA-3 and } \\
\text { increase of T-bet expression } \\
\text { Reduced the increased levels of IL-4, increased IFN-y, } \\
\text { and significantly inhibit all asthmatic reactions }\end{array}$ & {$[20]$} \\
\hline & $10 \mathrm{mg} / \mathrm{kg}$ & $\mathrm{BALB} / \mathrm{C}$ & $\begin{array}{l}\text { Reduced eosinophil counts in BALF, blood and lung } \\
\text { parenchyma }\end{array}$ & {$[29]$} \\
\hline & $10 \mathrm{mg} / \mathrm{kg}$ & $\mathrm{BALB} / \mathrm{C}$ & $\begin{array}{l}\text { Reduced the eosinophil recruitment, IL-4 and IL-5 levels } \\
\text { in the BALF, as well as, inhibited the NF-KB activation, } \\
\text { P-selectin expression and the mucus production in } \\
\text { the lung }\end{array}$ & {$[17]$} \\
\hline & $5 \mathrm{mg} / \mathrm{kg}$ & Sprague-Dawley rats & $\begin{array}{l}\text { Diminished the increase of total cell numbers and } \\
\text { macrophage numbers in BALF } \\
\text { Decreased the neutrophil and lymphocyte counts, levels } \\
\text { of TNF- } a, I L-1 \beta \text {, and IL-6 }\end{array}$ & {$[30]$} \\
\hline & $16 \mathrm{mg} / \mathrm{kg}$ & $\mathrm{BALB} / \mathrm{C}$ & $\begin{array}{l}\text { Lower epithelial thickness, subepithelial smooth muscle } \\
\text { thickness, goblet, and mast cell numbers } \\
\text { Lower IL-25, IL-33, TSLP, caspase-3 and TUNEL }\end{array}$ & {$[31]$} \\
\hline \multirow[t]{3}{*}{ Allergic rhinitis } & 460 mg of herbal extract & Not animals. In AR patients & Reduced total serum IgE & {$[43]$} \\
\hline & $25 \mathrm{mg} / \mathrm{kg}$ & Sprague-Dawley rats & Inhibit nasal rubbing movements and sneezing & {$[44]$} \\
\hline & $80 \mathrm{mg} / \mathrm{kg}$ & Sprague-Dawley rats & $\begin{array}{l}\text { Suppressed of AR } \\
\text { Weaker COX-2 and VIP expressions }\end{array}$ & {$[45]$} \\
\hline \multirow[t]{4}{*}{ Atopic dermatitis } & - & $\mathrm{Nc/Nga} \mathrm{mouse}$ & $\begin{array}{l}\text { Suppressed angiogenesis and Th2-related cytokine } \\
\text { expression }\end{array}$ & {$[53]$} \\
\hline & $10 \mathrm{mg}$ & Hsd:ICR (CD-1) mice & $\begin{array}{l}\text { Amelioration of the tissue damage, with a noticeable } \\
\text { attenuation of edema and leukocyte infiltration }\end{array}$ & {$[54]$} \\
\hline & $2 \mathrm{mg}$ & Nc/Nga mouse & $\begin{array}{l}\text { Decreased the iNOS and COX-2 mRNA expressions in the } \\
\text { skin as well as significantly suppressed the increase in } \\
\text { the level of total plasma IgE and eosinophils } \\
\text { Down-regulated the expression of the cytokines, IL-4, } 5 \\
\text { and } 13\end{array}$ & {$[50]$} \\
\hline & - & Nc/Nga mouse & $\begin{array}{l}\text { Weakened the development of AD-like skin lesions } \\
\text { Inhibited hyperkeratosis, parakeratosis, acanthosis, mast } \\
\text { cells and infiltration of inflammatory cells } \\
\text { Down-regulated cytoplasmic HMGB1, RAGE, nuclear } \\
\text { p-NF-kB, p-extracellular signal-regulated kinase (ERK) } \\
\text { 1/2, COX2, TNFa, IL-1 } \beta, \text { IL-2Ra, IFNy and IL-4 and } \\
\text { up-regulated nuclear Nrf2 }\end{array}$ & {$[55]$} \\
\hline
\end{tabular}

sRaw specific airway resistance, LAR late-phase response, IAR immediate phase response, BALF bronchoalveolar lavage fluid, TSLP thymic stromal lymphopoietin, VIP vasoactive intestinal polypeptide, COX cyclooxygenase, Nrf2 nuclear factor erythroid 2-related factor 2, HMGB high mobility group box, RAGE receptor for advanced glycation end product, NF-KB nucleartranscription factor kappa $B$ 
contraction. In 2006, Nanua et al. have hypothesized that quercetin blocks airway epithelial cells chemokine expression via phosphatidylinositol (PI) 3 kinasedependent mechanism. They showed that quercetin $(3,3,4,5,7$ pentahydroxy flavone) blocks the airway epithelial cell IL-8 and monocyte chemoattractant protein $(\mathrm{MCP})-1$ expression by attenuating the signaling through a PI-3 kinase/Akt/NF-KB pathway and also inhibits chemokine expression via transcriptional and posttranscriptional ways. Quercetin inhibits allergen sensitization, induced MCP-1 expression, and airways hyperresponsiveness, in vivo [32]. In 2011, the acute effect of quercetin on experimental allergic asthma after single-dose oral administration in vivo and in vitro was investigated by Joskova et al. They showed that quercetin (20 $\mathrm{mg} / \mathrm{kg}$ ) caused significant bronchodilation, both in vivo and in vitro. They concluded that quercetin could prove its ability to reduce the hyperreactivity of airways in laboratory conditions as one of the main features of allergic asthma [6]. In 2012, the effect of quercetin on mast cell activation in vitro and in vivo has been investigated by Cruz et al. They demonstrated that treatment with quercetin decrease allergen-induced development of airway hyperresponsiveness, TH2 responses in the lung, lung eosinophilia, and goblet cell metaplasia after allergen exposure to sensitized host [33]. The effect of quercetin on cytokine levels have been investigated in two studies. In 2013, Sakai-Kashiwabara et al. studied the influence of quercetin on eosinophil functions. The first set of experiments was undertaken to examine whether quercetin could suppress eosinophilia and IgE hyperproduction induced by Mesocestoides corti infection in BALB/c mice. Quercetin exerts suppressive effects on eosinophil activation, but not eosinophil growth and IgE hyperproduction. Therefore, quercetin will be a useful supplement for the management of eosinophil-mediated diseases, such as AR and asthma [34]. In 2015, the effect of quercetin on cytokine levels and smooth muscle contraction, in vitro and its therapeutic potential effect on a murine model of asthma have been investigated by Oliveira et al. The study shows the reduction of inflammatory cytokines production, tracheal ring relaxation and also reduction of the total number of cells in BALF and eosinophil peroxidase in the lungs by treatment with quercetin. Quercetin is potentially active as anti-asthmatic drugs, they also have both immunomodulatory and bronchodilatory properties [35]. In 2013, Townsend et al. hypothesized that quercetin relaxes airway smooth muscles (ASM) via cAMP-mediated pathways and also amplifies $ß$-agonist relaxation. In in vitro assays, quercetin directly attenuated phospholipase C (PLC) activity, decreased inositol phosphate synthesis, and decreased intracellular calcium responses to Gq-coupled agonists (histamine or bradykinin). Finally, the nebulization of quercetin $(100 \mu \mathrm{M})$ in an in vivo model of airway responsiveness that increases airway resistance. Quercetin represented an entirely novel therapeutic option in the treatment of asthma due to its activity as both an inhaled phosphodiesterase 4 (PDE4) and also PLCB inhibitor with acute bronchodilator properties. Quercetin may has beneficial effects on relaxing ASM during an acute exacerbation while using alone or in combination with existing therapies such as short-acting $ß$-agonists. Additionally, in combination with recent work details about anti-inflammatory effects, quercetin may have been potential as an asthma therapy when using daily to prevent exacerbations [36]. In 2017, the effects of several herbs have been investigated by Luo et al. The study shows that quercetin could be used to develop new bronchodilators to treat obstructive lung diseases such as asthma and chronic obstructive pulmonary disease [37] (Table 3). Different effects of quercetin such as, inhibitory effect on mast cell activation, eosinophil activation, relaxation of tracheal ring, reduction in IL-4 and IgE serum, blocking airway epithelial cell IL-8 and MCP-1 expression suggest a valuable role of quercetin for allergic asthma. It is also suggested that quercetin might be a therapeutic candidate for allergic asthma and provide new insight into the immunopharmacological role of quercetin.

\section{Allergic rhinitis (AR)}

AR is a chronic inflammatory IgE-related disorder of the respiratory tract. AR has a high prevalence that affects up to $40 \%$ of the population, which results in labor loss, impaired quality of life, and comorbid diseases [38-40]. Numerous inflammatory cells, including mast cells, $\mathrm{CD}^{+} \mathrm{T}$ cells, B cells, macrophages, and eosinophils, infiltrate the nasal lining in AR patients after exposure to an inciting allergen (most commonly airborne dust mite fecal particles, cockroach residues, animal dander, molds, and pollens). In allergic individuals, the $\mathrm{T}$ cells which are infiltrating the nasal mucosa are predominantly $\mathrm{Th} 2$ in nature and release cytokines (e.g., IL-3, IL-4, IL-5, and IL-13) that promote IgE production by plasma cells. Crosslinking of IgE bound to mast cells by allergens, in turn, triggers the release of mediators, such as histamine and leukotrienes that are responsible for arteriolar dilation, increased vascular permeability, itching, rhinorrhea, mucus secretion, and smooth muscle contraction in the lung. The mediators and cytokines released during the early phase of an immune response to an inciting allergen trigger a further cellular inflammatory response over the next $4-8 \mathrm{~h}$ (late-phase inflammatory response) 
Table 3 Summary of main effects of quercetin on allergic diseases (in vitro and in vivo studies)

\begin{tabular}{|c|c|c|c|c|c|}
\hline Diseases & Dosage & Cell/cell line & Animal & Quercetin's effect & References \\
\hline \multirow[t]{7}{*}{ Allergic asthma } & $0.1-25 \mu \mathrm{M}$ & 16HBE140 & $\mathrm{BALB} / \mathrm{C}$ & $\begin{array}{l}\text { Blocks airway epithelial cell } \\
\text { IL-8 and MCP-1 expression } \\
\text { by attenuating the signaling } \\
\text { through a PI-3 kinase/Akt/NF-KB } \\
\text { pathway } \\
\text { Inhibits chemokine expression } \\
\text { Inhibits allergen sensitization, } \\
\text { induced monocyte } \\
\text { chemoattractant protein } \\
\text { (MCP)-1 expression, and airways } \\
\text { hyperresponsiveness, in vivo }\end{array}$ & [32] \\
\hline & $20 \mathrm{mg} / \mathrm{kg}$ & $\begin{array}{l}\text { Spinal cord-tracheal smooth } \\
\text { muscle }\end{array}$ & Male guinea pig & $\begin{array}{l}\text { Caused significant } \\
\text { bronchodilation, both in vivo } \\
\text { and in vitro }\end{array}$ & [6] \\
\hline & $30 \mathrm{mg} / \mathrm{kg}$ & Bone marrow-derived mast cells & $\mathrm{BALB} / \mathrm{C}$ & $\begin{array}{l}\text { Decrease allergen-induced } \\
\text { development of airway } \\
\text { hyperresponsiveness, TH2 } \\
\text { responses in the lung, lung } \\
\text { eosinophilia, and goblet cell } \\
\text { metaplasia }\end{array}$ & [33] \\
\hline & $\begin{array}{l}\text { Various dose } \\
\text { Min-max }(5-20 \mathrm{mg} / \mathrm{kg})\end{array}$ & Eosonophil & $\mathrm{BALB} / \mathrm{C}$ & $\begin{array}{l}\text { Suppressive effects on eosinophil } \\
\text { activation }\end{array}$ & [34] \\
\hline & $30 \mathrm{mg} / \mathrm{kg}$ & Spleen-tracheal smooth muscle & $\mathrm{A} / \mathrm{J}$ mice & $\begin{array}{l}\text { Reduction of inflammatory } \\
\text { cytokines production, tracheal } \\
\text { rings relaxation and also } \\
\text { reduction of the total number } \\
\text { of cells in BALF and eosinophil } \\
\text { peroxidase in lungs }\end{array}$ & {$[35]$} \\
\hline & $100 \mu \mathrm{M}$ & Human ASM cells & A/J mice & $\begin{array}{l}\text { Attenuated PLC activity, } \\
\text { decreased inositol phosphate } \\
\text { synthesis, and decreased } \\
\text { intracellular calcium responses } \\
\text { to Gq-coupled agonists in vitro } \\
\text { Increase of airway resistance } \\
\text { in vivo }\end{array}$ & [36] \\
\hline & - & Human ASM cells & $\mathrm{BALB} / \mathrm{C}$ & $\begin{array}{l}\text { Treat obstructive lung diseases } \\
\text { such as asthma and chronic } \\
\text { obstructive pulmonary disease }\end{array}$ & [37] \\
\hline Allergic rhinitis & $20 \mathrm{mg} / \mathrm{kg}$ & HNEpC & $\mathrm{BALB} / \mathrm{C}$ & $\begin{array}{l}\text { Inhibited nasal symptoms and } \\
\text { increased TRX levels in nasal } \\
\text { lavage fluids }\end{array}$ & [47] \\
\hline Atopic dermatitis & $10 \mathrm{mg} / \mathrm{ml}$ & Skin biopsies & Hsd:ICR (CD-1) mice & $\begin{array}{l}\text { Prevented the formation of skin } \\
\text { lesions abrogating the various } \\
\text { biochemical processes that } \\
\text { cause epithelial loss and skin } \\
\text { damage }\end{array}$ & {$[56]$} \\
\hline
\end{tabular}

MCP monocyte chemoattractant protein, $P L C$ phospholipase $C, T R X$ thioredoxin, BALF bronchoalveolar lavage fluid

resulting in recurrent symptoms (usually nasal congestion) that often persist [40-42]. A lot of medical treatment modalities used as a treatment of AR, such as antihistamines, steroids, montelukast (Singulair), and immunotherapy. However, these therapeutic modalities can fail on some occasions [42]. Thus, in vitro and in vivo studies have been managed to make AR models and these studies also assess the effects of different agents such as quercetin.

\section{Effect of quercetin on AR} In vitro studies

Two in vitro studies have investigated the effect of quercetin on human nasal epithelial cells (HNEpC). The quercetin influences on the production of both substances including periostin, a $90-\mathrm{kDa}$ extracellular matrix protein that is attracting attention as a novel biomarker of airway inflammatory diseases such as $\mathrm{AR}$ and asthma, and periostin-induced eosinophil chemoattractants from HNEpC have been examined 
by Irie et al. Treatment of HNEpC with quercetin at a concentration of $4.0 \mu \mathrm{M}$ suppressed the ability of cells to produce CC-chemokine ligand 5 (CCL5) and eotaxin. These results showed that quercetin can suppress the production of both periostin and periostin-induced eosinophil chemoattractants from HNEpC and results in the improvement of the clinical condition of AR [38]. In 2018, the influence of quercetin on nitric oxide (NO) production from HNEpC after IL-4 stimulation has been investigated by Ebihara et al. The results significantly remarked that quercetin modified the clinical condition of RA through the suppression of NO production from nasal epithelial cells after IL- 4 stimulation. The minimum concentration of quercetin that caused significant suppression was $1.0 \mathrm{nM}$ [41] (Table 1). It can be suggested that quercetin has a valuable effect on AR by influencing on $\mathrm{HNEpC}$. More in vitro studies is required to clarify the exact role of quercetin on immune cells in AR patients.

\section{In vivo studies}

Increased levels of IgE are a hallmark of allergic diseases. A proper treatment for allergic diseases should be able to reduce serum IgE levels. In 2001, the effects of Biminne, a kind of Chinese herbal formulation in patients struggling with moderate to severe perennial AR have been determined by $\mathrm{Hu}$ et al. Quercetin and baicalein are two major flavonoids in Biminne. A pilot dose-response study showed both half ( $230 \mathrm{mg}$ of herbal extract) and full (460 mg of herbal extract) strengths were effective. Total serum IgE was reduced after the herbal treatment. The results suggest that the Biminne formulation is effective in the treatment of perennial AR. The mechanism of action is unknown [43]. Reduction in the symptoms of AR has been demonstrated in the study of Kashiwabara et al. They examined the influence of quercetin on the development of AR by using Sprague-Dawley rats. The results demonstrated that oral administration of quercetin for 5 and 7 days could inhibit nasal rubbing movements and sneezing. The minimum dose that caused significant inhibition was $25 \mathrm{mg} / \mathrm{kg}$. The results strongly suggested that quercetin will be well-qualified as a supplement for the management and treatment of allergic diseases, especially AR [44]. In 2017, Sagit et al. have been noticed that quercetin had a therapeutic effect on an experimental rat model of AR. They observed that AR was suppressed in the quercetin (dose: $80 \mathrm{mg} /$ $\mathrm{kg}$ ) group comparing to the control group. In immune histochemical evaluation, it was detected that COX-2 and vasoactive intestinal polypeptide (VIP) expressions were weaker in the quercetin group than the control group. According to these findings, they concluded that quercetin was effective in AR-induced by OVA in rats both histopathologically and serologically [45] (Table 2).

\section{In vitro and in vivo studies}

Thioredoxin (TRX) is a protein that regulates reactive oxidative metabolism and scavenges reacting oxygen species, which is implicated in the mechanism of asthma. Some studies have shown that TRX suppresses allergic inflammation [46]. In 2018, the effects of quercetin on AR symptoms and the role of the TRX production of nasal epithelial cells in vitro and in vivo have been investigated by Edo et al. The results showed that the oral administration of $20 \mathrm{mg} / \mathrm{kg}$ of quercetin significantly inhibited nasal symptoms and the same dose of quercetin significantly increased TRX levels in nasal lavage fluids. Quercetin's ability to increase TRX production may be useful, at least in part, for its clinical efficacy toward AR [47] (Table 3). Similar to asthma allergic, quercetin seems to be a good therapeutic candidate for AR. However, the study of quercetin on AR is lower than asthma allergic. Similar to studies on asthma allergic, the dose of $25 \mathrm{mg} /$ $\mathrm{kg}$ quercetin seems to be enough for inhibiting the symptoms in AR.

\section{Atopic dermatitis (AD)}

$\mathrm{AD}$ is chronic, inflammatory skin disease, with a prevalence of up to $7 \%$ in adults and up to $25 \%$ among children. Different mechanisms including environmental, psychological, immunological, pharmacological, and genetic factors play role in $\mathrm{AD}$ pathogenesis. In fact, 31 risk loci associated with $\mathrm{AD}$ have been identified. Characteristically, symptoms start within the first 5 years of life, and in adults, the disease has generally been present for decades [48, 49].

$\mathrm{AD}$ is considered a primarily $\mathrm{T}$ cell-driven disease as proved by the clinical efficacy of broad $\mathrm{T}$ cell-targeting therapeutics, such as cyclosporine, efalizumab, and alefacept. Although efalizumab and alefacept are no longer available because of safety concerns, cyclosporine, oral glucocorticoid steroids, and phototherapy (narrowband UVB) are often used to treat moderate-to-severe disease. However, cyclosporine and, even more so, glucocorticoid steroids are not suitable for long-term use because of multiple side effects. Phototherapy is too time consuming and not feasible for most patients. Therefore, AD presents a large unmet need for both effective and safe therapeutics $[49,50]$. Based on side effects of therapeutic agents which are used for AD, several studies have investigated the effects of quercetin in AD. 


\section{Effect of quercetin on AD In vitro studies}

Two studies have examined the effect of quercetin on heme oxygenase (HO) and oxidative stress. In 2009, the role of $\mathrm{HO}-1$ in the anti-allergic action of quercetin against the degranulation of rat basophilic leukemia (RBL-2H3) cells, rat peritoneal mast cells, and mouse bone marrow-derived mast cells has been investigated by Matsushima et al. HO activity was upregulated after short exposure to quercetin, followed by the induction of $\mathrm{HO}-1$ expression after long exposure to quercetin. The results strongly suggest that quercetin exerted anti-allergic actions via activation of nuclear factor erythroid 2-related factor 2 (Nrf2(-HO-1 pathways [51]. The improvement of quercetin protective effect against oxidative stress skin damage by incorporation in nanovesicles has been evaluated by Manca et al. Quercetin was taking part in glycerosomes, new phospholipid-glycerol vesicles, and their protective effect against oxidative stress skin damages has been assessed. Quercetin incorporated into liposomal and glycerosomal nanoformulations showed a strong ability to scavenge free radicals and protect human keratinocytes in vitro against hydrogen peroxide damage. Moreover, quercetin-loaded vesicles were avidly taken up by keratinocytes in vitro. Overall, results indicate 40 and 50\% glycerosomes as promising nanosystems for the improvement of cutaneous quercetin delivery and keratinocyte protection against oxidative stress damage [52] (Table 1).

\section{In vivo studies}

The effect of quercetin on Th2-related cytokines which are crucial in allergic diseases has been studied by Jung et al. in 2010. They reported that tannic acid (TA) and quercetin suppressed angiogenesis and Th2-related cytokine expression including TSLP and thymus and activation-regulated chemokine (TARC), in an AD-like Nc/Nga mouse model. Furthermore, they have a therapeutic effect on $\mathrm{AD}$. TA and quercetin might be effective and improved therapeutic uses that should be investigated further for the treatment of AD [53]. In 2013, Caddeo et al. developed quercetin-loaded phospholipid vesicles, named liposomes and Penetration Enhancercontaining Vesicles (PEVs), and investigated the efficacy on tetradecanoylphorbol 13-acetate (TPA)-induced skin inflammation. The administration of vesicular quercetin on TPA-inflamed skin resulted in an amelioration of the tissue damage, with a noticeable attenuation of edema and leukocyte infiltration, especially using 5\% PEG-PEVs, confirmed by confocal microscopy. So, the proposed approach based on quercetin vesicular formulations may be valuable in the treatment of inflammatory skin disorders [54]. In 2014, Park et al. isolated quercetin-3-O( 2 "-gallate)-a-l-rhamnopyranoside (QGR) from the leaves of a native plant of Korea named Acer ginnala Maxim, and they evaluated the anti-inflammatory and antiallergic effect of QGR in a murine model of AD. Topical QGR significantly decreased the iNOS and COX-2 mRNA expressions in the skin as well as significantly suppressed the increase in the level of total plasma IgE and eosinophils. In addition, topical application of QGR down-regulated the expression of the cytokines, such as IL-4, 5 and 13, which were induced by Dermatophagoides farina ointment stimulation. So, the results demonstrate that QGR might be beneficial in the treatment of AD [50]. In 2015, the effects of quercetin on skin lesion, high mobility group box (HMGB) 1 cascade signaling and inflammation in the AD mouse model have been investigated by Karuppagoundera et al. AD-like lesion was induced by the application of house dust mite extract to the dorsal skin of NC/Nga transgenic mice. Quercetin treatment weakened the development of AD-like skin lesions. Histological analysis showed that quercetin inhibited hyperkeratosis, parakeratosis, acanthosis, mast cells and infiltration of inflammatory cells. Furthermore, quercetin treatment down-regulated cytoplasmic HMGB1, receptor for advanced glycation end product (RAGE), nuclear $\mathrm{p}-\mathrm{NF}-\mathrm{kB}$, p-extracellular signalregulated kinase (ERK) $1 / 2$, COX2, TNF $\alpha, I L-1 \beta, I L-2 R \alpha$, IFN- $\gamma$ and IL-4 and up-regulated nuclear Nrf2. Their data indicated that the HMGB1/RAGE/NF- $\mathrm{KB}$ signaling might play an important role in skin inflammation, and quercetin treatment could be a promising agent for $\mathrm{AD}$ by modulating the HMGB1/RAGE/NF- $\mathrm{kB}$ signaling and induction of Nrf2 protein [55] (Table 2).

\section{In vitro and in vivo studies}

In 2014, Castangia et al. developed biocompatible quercetin and curcumin nanovesicles as a novel approach to prevent and restore skin tissue defects on chronic cutaneous pathologies. Their results showed that nano entrapped polyphenols prevented skin lesions formation abrogating the various biochemical processes that cause epithelial loss and skin damage [56]. The effects of quercetin on $\mathrm{AD}$ seem to be similar to other allergic diseases. It suggested that quercetin affects different immune and non-immune cells in the same pathway (Table 3).

\section{Conclusion}

In the current article, we reviewed the effect of quercetin on allergic asthma, AR, and AD. Allergic diseases are a big concern and have high health care costs. In addition, the use of current therapies such as $ß 2$-agonists and corticosteroids has been limited 
for long term use due to their numerous side effects. Quercetin, which has a long story of usage in human history, has been demonstrated sufficient efficacy and has no significant side effects. It has the potential to reduce the most significant pathologies of asthma such as eosinophil and neutrophil recruitment, the activation of bronchial epithelial cells, collagen and mucus production and airway hyperactivity. It also can suppress the production of both periostin and periostin-induced eosinophil chemoattractants and resulting in the improvement of the clinical condition of AR. In fact, it will be a good candidate as a supplement for the management and treatment of allergic diseases, especially rhinitis. Since medicinal plants have a low price, natural origin, and fewer side effects, quercetin seems to be a good therapeutic nominee for allergic diseases in clinical trials.

\begin{abstract}
Abbreviations
BALF: Bronchoalveolar lavage fluid; COX: Cyclooxygenase; EGFR: Epidermal growth factor receptor; ERK: Extracellular-regulated kinase; HMGB: High mobility group box; HNE: Human neutrophil elastase; HNEpC: Human nasal epithelial cells; HO: Heme oxygenase; IAR: Immediate phase response; LAR: Late-phase response; MCP: Monocyte chemoattractant protein; MUC5AC: Mucin 5 AC; NF-KB: Nucleartranscription factor kappa B; NO: Nitric oxide; Nrf2: Nuclear factor erythroid 2-related factor 2; PKC: Protein kinase C; PLC: Phospholipase C; RA: Allergic rhinitis; RAGE: Receptor for advanced glycation end product; RANTES: Regulated on activation, normal t cell expressed and secreted; sRaw: Specific airway resistance; TRX: Thioredoxin; TSLP: Thymic stromal lymphopoietin; VIP: Vasoactive intestinal polypeptide.
\end{abstract}

\section{Acknowledgements}

None.

\section{Authors' contributions}

MJ drafted the manuscript, reviewed the literature and critically reviewed the final manuscript, MSH and NF drafted the manuscript, NK provided the figures, FF and MGH reviewed the manuscript, NE supervised, conceived and reviewed the manuscript. All authors read and approved the final manuscript.

\section{Funding}

This research did not receive any specific grant from funding agencies in the public, commercial, or not-for-profit sectors.

\section{Availability of data and materials}

Not applicable.

\section{Ethics approval and consent to participate}

Not applicable.

\section{Consent for publication}

Not applicable.

\section{Competing interests}

The authors declare that they have no competing interests.

\section{Author details}

${ }^{1}$ Department of Immunology, Faculty of Medicine, Isfahan University of Medical Sciences, Box 8174673461, Isfahan, Iran. ${ }^{2}$ Applied Physiology Research Center, Isfahan Cardiovascular Research Institute, Department of Physiology, School of Medicine, Isfahan University of Medical Sciences, Isfahan, Iran.
Received: 15 October 2019 Accepted: 7 May 2020

Published online: 14 May 2020

\section{References}

1. Jafarinia M, Jafarinia M. A review of medicinal properties of some Asteraceae family plants on immune system. Rep Health Care. 2019:5(2):1-7.

2. LiY, et al. Quercetin, inflammation and immunity. Nutrients. 2016;8(3):167.

3. Wiczkowski W, et al. Quercetin from shallots (Allium cepa L. var. aggregatum) is more bioavailable than its glucosides. J Nutr. 2008;138(5):885-8.

4. Williamson G, Manach C. Bioavailability and bioefficacy of polyphenols in humans. II. Review of 93 intervention studies. Am J Clin Nutr. 2005;81(1):243S-55S.

5. Bhagwat S, Haytowitz DB, Holden JM. USDA database for the flavonoid content of selected foods, Release 3.1. US Department of Agriculture: Beltsville, MD, USA, 2014.

6. Harwood M, et al. A critical review of the data related to the safety of quercetin and lack of evidence of in vivo toxicity, including lack of genotoxic/carcinogenic properties. Food Chem Toxicol. 2007:45(11):2179-205.

7. Gupta A, et al. Quercetin: a wonder bioflavonoid with therapeutic potential in disease management. Asian Pac J Trop Dis. 2016;6(3):248-52.

8. Lakhanpal P, Rai DK. Quercetin: a versatile flavonoid. Internet J Med Update. 2007;2(2):22-37.

9. Mlcek J, et al. Quercetin and its anti-allergic immune response. Molecules. 2016;21(5):623.

10. Ghosh B. Quercetin inhibits LPS-induced nitric oxide and tumor necrosis factor-a production in murine macrophages. Int J Immunopharmacol. 1999;21 (7):435-43.

11. Geraets $L$, et al. Dietary flavones and flavonoles are inhibitors of poly (ADP-ribose) polymerase-1 in pulmonary epithelial cells. J Nutr. 2007:137(10):2190-5.

12. Bureau G, Longpré F, Martinoli MG. Resveratrol and quercetin, two natural polyphenols, reduce apoptotic neuronal cell death induced by neuroinflammation. J Neurosci Res. 2008;86(2):403-10.

13. Lee KM, et al. Protective effect of quercetin against arsenite-induced COX-2 expression by targeting PI3K in rat liver epithelial cells. J Agric Food Chem. 2010;58(9):5815-20.

14. Kempuraj $\mathrm{D}$, et al. Flavonols inhibit proinflammatory mediator release, intracellular calcium ion levels and protein kinase $C$ theta phosphorylation in human mast cells. Br J Pharmacol. 2005;145(7):934-44

15. Formica J, Regelson W. Review of the biology of quercetin and related bioflavonoids. Food Chem Toxicol. 1995;33(12):1061-80.

16. Joskova M, Franova S, Sadlonova V. Acute bronchodilator effect of quercetin in experimental allergic asthma. Bratisl Lek Listy. 2011:112(1):9-12.

17. Rogerio AP, et al. Anti-inflammatory effect of quercetin-loaded microemulsion in the airways allergic inflammatory model in mice. Pharmacol Res. 2010;61(4):288-97.

18. Oja A. The inhibitory effects of flavonoids on chemokine function in allergic asthma and food allergy. 2014

19. Fortunato $L R$, et al. Quercetin: a flavonoid with the potential to treat asthma. Braz J Pharm Sci. 2012:48(4):589-99.

20. Park $H-J$, et al. Quercetin regulates Th1/Th2 balance in a murine model of asthma. Int Immunopharmacol. 2009:9(3):261-7.

21. Jung $\mathrm{CH}$, et al. Anti-asthmatic action of quercetin and rutin in conscious guinea-pigs challenged with aerosolized ovalbumin. Arch Pharmacal Res. 2007;30(12):1599.

22. Romagnani S. Immunologic influences on allergy and the $\mathrm{TH} 1 / \mathrm{TH} 2$ balance. J Allergy Clin Immunol. 2004;113(3):395-400.

23. Chabra R, Gupta M. Allergic and environmental induced asthma. In: StatPearls. StatPearls Publishing; 2019

24. Capasso R, et al. Inhibitory effect of quercetin on rat trachea contractility in vitro. J Pharm Pharmacol. 2009:61(1):115-9. 
25. Chang JH, et al. Dietary polyphenols affect MUC5AC expression and ciliary movement in respiratory cells and nasal mucosa. Am J Rhinol Allergy. 2010;24(2):e59-62.

26. Li N, et al. The effect of quercetin on human neutrophil elastaseinduced mucin5AC expression in human airway epithelial cells. Int Immunopharmacol. 2012;14(2):195-201.

27. Moon $\mathrm{H}$, et al. Quercetin inhalation inhibits the asthmatic responses by exposure to aerosolized-ovalbumin in conscious guinea-pigs. Arch Pharmacal Res. 2008;31(6):771.

28. Zhu JX, et al. Quercetin, kaempferol and isorhamnetin in Elaeagnus pungens Thunb. leaf: pharmacological activities and quantitative determination studies. Chem Biodivers. 2018;15(8):e1800129.

29. Rogerio A, et al. Anti-inflammatory activity of quercetin and isoquercitrin in experimental murine allergic asthma. Inflamm Res. 2007;56(10):402-8.

30. Baowen $\mathrm{Q}$, et al. A further investigation concerning correlation between anti-fibrotic effect of liposomal quercetin and inflammatory cytokines in pulmonary fibrosis. Eur J Pharmacol. 2010;642(1-3):134-9.

31. Sozmen SC, et al. Effects of quercetin treatment on epithelium-derived cytokines and epithelial cell apoptosis in allergic airway inflammation mice model. Iran J Allergy Asthma Immunol. 2016;15(6):487-97.

32. Nanua S, et al. Quercetin blocks airway epithelial cell chemokine expression. Am J Respir Cell Mol Biol. 2006;35(5):602-10.

33. Cruz $\mathrm{E}$, et al. Kalanchoe pinnata inhibits mast cell activation and prevents allergic airway disease. Phytomedicine. 2012;19(2):115-21.

34. Sakai-Kashiwabara M, Asano K. Inhibitory action of quercetin on eosinophil activation in vitro. Evid Based Complement Alternat Med. 2013:2013:127105.

35. Oliveira TT, et al. Potential therapeutic effect of Allium cepa L. and quercetin in a murine model of Blomia tropicalis induced asthma. DARU J Pharm Sci. 2015;23(1):18.

36. Townsend EA, Emala CW Sr. Quercetin acutely relaxes airway smooth muscle and potentiates $\beta$-agonist-induced relaxation via dual phosphodiesterase inhibition of PLC $\beta$ and PDE4. Am J Physiol Lung Cell Mol Physiol. 2013;305(5):L396-403.

37. Luo X, et al. Polygonum aviculare L. extract and quercetin attenuate contraction in airway smooth muscle. Sci Rep. 2018;8(1):3114.

38. Irie $S$, et al. Suppressive activity of quercetin on periostin functions in vitro. In Vivo. 2016;30(1):17-25.

39. Otsuka $\mathrm{H}$, et al. Histochemical and functional characteristics of metachromatic cells in the nasal epithelium in allergic rhinitis: studies of nasal scrapings and their dispersed cells. J Allergy Clin Immunol. 1995:96(4):528-36.

40. Thornhill SM, Kelly A-M. Natural treatment of perennial allergic rhinitis. Altern Med Rev. 2000:5(5):448-54

41. Ebihara $\mathrm{N}$, et al. Suppressive effect of quercetin on nitric oxide production from nasal epithelial cells in vitro. Evid Based Complement Alternat Med. 2018;2018:6097625

42. Kulka M. The potential of natural products as effective treatments for allergic inflammation: implications for allergic rhinitis. Curr Top Med Chem. 2009;9(17):1611-24.
43. Hu G, et al. The Chinese herbal formulation biminne in management of perennial allergic rhinitis: a randomized, double-blind, placebocontrolled, 12-week clinical trial. Ann Allergy Asthma Immunol. 2002;88(5):478-87.

44. Kashiwabara M, et al. Suppression of neuropeptide production by quercetin in allergic rhinitis model rats. BMC Complement Altern Med. 2016:16(1):132.

45. Sagit $M$, et al. Effectiveness of quercetin in an experimental rat model of allergic rhinitis. Eur Arch Otorhinolaryngol. 2017;274(8):3087-95.

46. Ito W, et al. Thioredoxin in allergic inflammation. Int Arch Allergy Immunol. 2011;155(Suppl. 1):142-6.

47. Edo Y, Otaki A, Asano K. Quercetin enhances the thioredoxin production of nasal epithelial cells in vitro and in vivo. Medicines. 2018;5(4):124.

48. Choopani $R$, et al. Treatment of atopic dermatitis from the perspective of traditional Persian medicine: presentation of a novel therapeutic approach. J Evid Based Complement Altern Med. 2017;22(1):5-11.

49. Karuppagounder $\vee$, et al. Molecular targets of quercetin with antiinflammatory properties in atopic dermatitis. Drug Discov Today. 2016;21(4):632-9.

50. Park EJ, et al. Effect of topical application of quercetin-3-O-(2"'-gallate)-aI-rhamnopyranoside on atopic dermatitis in NC/Nga mice. J Dermatol Sci. 2015;77(3):166-72.

51. Matsushima M, et al. Heme oxygenase- 1 mediates the antiallergic actions of quercetin in rodent mast cells. Inflamm Res. 2009;58(10):705-15.

52. Manca ML, et al. Improvement of quercetin protective effect against oxidative stress skin damages by incorporation in nanovesicles. Colloids Surf B. 2014;123:566-74.

53. Jung MK, et al. Tannic acid and quercetin display a therapeutic effect in atopic dermatitis via suppression of angiogenesis and TARC expression in Nc/Nga mice. J Investig Dermatol. 2010;130(5):1459-63.

54. Caddeo C, et al. Topical anti-inflammatory potential of quercetin in lipid-based nanosystems: in vivo and in vitro evaluation. Pharm Res. 2014;31(4):959-68.

55. Karuppagounder $\mathrm{V}$, et al. Modulation of HMGB 1 translocation and RAGE/ NF $\mathrm{kB}$ cascade by quercetin treatment mitigates atopic dermatitis in NC/ Nga transgenic mice. Exp Dermatol. 2015;24(6):418-23.

56. Castangia l, et al. Fabrication of quercetin and curcumin bionanovesicles for the prevention and rapid regeneration of full-thickness skin defects on mice. Acta Biomater. 2014;10(3):1292-300.

\section{Publisher's Note}

Springer Nature remains neutral with regard to jurisdictional claims in published maps and institutional affiliations.
Ready to submit your research? Choose BMC and benefit from:

- fast, convenient online submission

- thorough peer review by experienced researchers in your field

- rapid publication on acceptance

- support for research data, including large and complex data types

- gold Open Access which fosters wider collaboration and increased citations

- maximum visibility for your research: over 100M website views per year

At BMC, research is always in progress.

Learn more biomedcentral.com/submissions 